\title{
Pelaksanaan Literasi Membaca di Sekolah Dasar
}

\section{Annisa Putri Bungsu1*, Febrina Dafit ${ }^{2}$}

1,2 Jurusan Pendidikan Guru Sekolah Dasar, Universitas Islam Riau, Riau, Indonesia

\section{ART ICLE INFO}

\section{Article history:}

Received August 02, 2021

Revised August 03, 2021

Accepted September 14, 2021

Available online October 25, 2021

Kata Kunci:

Pelaksanaan, Literasi, Membaca

Keywords:

Implementation, Literacy, Reading

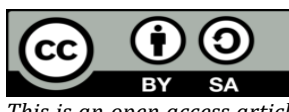

This is an open access article under the $\underline{C C}$ BY-SA license.

Copyright (C) 2021 by Author. Published by Universitas Pendidikan Ganesha.

\begin{abstract}
A B S T R A K
Gerakan Literasi sekolah (GLS) yang sedang dijalankan oleh pemerintah dilakukan dengan tujuan untuk meningkatkan minat baca dan membiasakan siswa untuk membaca buku walau hanya selembar. Hanya saja tidak semua sekolah mampu menjalankan GLS dengan baik, sehingga perlu adanya evaluasi terhdap pelaksanaan GLS. Adapun tujuan dari penelitian yakni untuk mengetahui mengetahui proses pengembangan dan faktor pendukung dan penghambat literasi membaca. Penelitian merupakan jenis penelitian deskriptif dengan menggunakan pendekatan kualitatif. Subjek yang terlibat dalam penelitian ini yakni guru dan siswa kelas V SD. Pengumpulan data dalam penelitian dilakukan dengan metode wawancara, observasi, dan dokumentasi. Data yang diperoleh pada penelitian ini kemudian dianalisis dengan menggunakan analisis deskriptif kualitatif dan difokuskan dengan menggunakan model Miles \& Huberman yang terdiri dari tahap reduksi data, penyajian, dan penarikan kesimpulan. Hasil analisis penelitian menunjukkan bahwa kegiatan literasi dilaksanakan dengan mengajak siswa membaca cerita, membuat karya tulis, menganalisis isi teks, menggambarkan inferensi analitis atas teks, mengkritik teks dan menampilkan secara kreatif. Dimana semua kegiatan tersebut telah mampu diikuti dengan baik oleh siswa walaupun terdapat beberapa kendala di dalamnya.
\end{abstract}

\begin{abstract}
A B S T R A C T
The School Literacy Movement (GLS) which is being run by the government is carried out to increase interest in reading and familiarizing students with reading books, even if only a sheet. It's just that not all schools can run the GLS well, so it is necessary to evaluate the implementation of the GLS. This study aims to find out the development process and the supporting and inhibiting factors of reading literacy. This research is a type of descriptive research using a qualitative approach. The subjects involved in this study were teachers and students of fifth grade elementary school. Data collection in the study was carried out by interview, observation, and documentation methods. The data obtained in this study were then analyzed using qualitative descriptive analysis and focused using the Miles \& Huberman model consisting of data reduction, presentation, and conclusion drawing. The results of the research analysis show that literacy activities are carried out by inviting students to read stories, make written works, analyze text content, describe analytical inferences on texts, criticize texts and present creatively. Where all these activities have been able to be followed well by students even though there are some obstacles in them.
\end{abstract}

\section{PENDAHULUAN}

Pendidikan merupakan suatu proses pembelajaran yang dilakukan dengan memberikan berbagai pemahaman dan pengalaman kepada siswa dalam bentuk kesempatan belajar, sehingga siswa mampu memahami konsep yang utuh serta mampu meningkatkan sumber dayanya (Alpian \& Anggraeni, 2019; Hendriana \& Jacobus, 2016). Pendidikan tidak hanya dipandang sebagai media dalam menyampaikan suatu pengetahuan dari satu generasi ke generasi selanjutnya, melainkan suatu media yang diharapkan dapat membawa perubahan dalam perkembangan kehidupan bangsa (Ariyanti, 2017). Di Indonesia pelaksanaan pendidikan tidak hanya difokuskan terhadap pengembangan ilmu pengetahuan dan teknologi, tetapi juga difokuskan terhadap pembetukan sikap, serta peningkatan kepekaan sosial agar mampu mengkaji seperangkat peristiwa, fakta, konsep, dan generalisasi yang berkaitan dengan lingkungan (Astawa, 2017; Sujana, 2019). Pelaksanaan pendidikan di Indonesia lebih banyak diaktualisasikan dalam kegiatan membaca (Megantara \& Wachid, 2021). Membaca menjadi salah satu fungsi penting dalam hidup (Elendiana, 2020; Ismaniar, 2018). Semua proses belajar didasarkan pada kemampuan membaca. Dengan kemampuan membaca yang membudaya dalam diri setiap anak, maka tingkat keberhasilan di sekolah maupun dalam kehidupan di masyarakat akan membuka peluang kesuksesan hidup yang lebih baik (Syahidin, 2020; Teguh, 2017). Membaca merupakan suatu keterampilan yang dapat menjadi faktor penunjang dalam kemampuan berbahasa lainnya seperti berbicara dan juga menulis (Rohman, 2017). Di era globalisasi dan perkembangan teknologi informasi 
seperti saat ini kemampuan membaca memiliki peran penting untuk membuka jendela informasi masyarakat (Setiawan, 2018). Melalui kegiatan membaca seseorang dapat menggali berbagai informasi, pengetahuan, dan pengalaman baru, hal ini dikarenakan aktifitas membeca bersifat reseptif atau menerima (Fitriana \& Ridlwan, 2021; Mirna \& Rambe, 2021). Pengatahuan dan informasi yang diperoleh pada kegiatan membaca akan menjadi pintu untuk membuka wawasan yang selanjutnya dapat merubah paradigma dalam berpikir dan bertindak seseorang menuju kemajuan (Megantara \& Wachid, 2021).

Hanya saja kenyataan dilapangan menunjukkan bahwa minat baca masyarakat Indonesia masih sangat rendah (Lubis, 2018; Sudiana, 2020). Hal ini ditunjukkan dengan masih tingginya angka masyarakat buta aksara di Indonesia (Kamardana et al., 2021; Sariani, 2020). Menumbuhkan minat baca siswa dan masyarakat merupakan suatu hal yang sangat sulit untuk dilakukan, hal dikarenakan kurangnya keinginan, kemauan dan dorongan dari diri sendiri. Hal ini sejalan dengan temuan hasil wawancara yang telah dilakukan bersama seorang wali kelas V SDN 004 Ukui. Berdasarkan kegiatan wawancara, didapatkan informasi bahwa minat baca siswa kelas V masih tergolong rendah, hal ini terlihat dari kurangnya kemampuan siswa dalam menguraikan isi bacaan dan biasanya siswa hanya membaca saja tanpa tahu isi bacaan tersebut. Rendahnya minat baca siswa dan masyarakat tentunya akan berdampak buruk pada kemajuan bangsa, kualitas pendidikan akan semakin menurun dan tingkat buta aksara akan semakin meningkat. Untuk mengatasi permasalahan mengenai rendahnya minat baca siswa dan masyarakat. Pemerintah mulai menggalangkan program GLS (gerakan literasi sekolah). Gerakan Literasi Sekolah merupakan bagian dari kegiatan Gerakan Literasi Nasional yang dicanangkan Pada tahun 2016 oleh Kementerian Pendidikan dan Kebudayaan sebagai lembaga yang memilki kewenangan dalam bidang pendidikan (Khotimah et al., 2018; Megantara \& Wachid, 2021; Wandasari, 2017). Program ini merupakan perwujudan dari peraturan menteri pendidikan dan Kebudayaan Nomor 23 Tahun 2015 tentang budi pekerti, yang memiliki tujuan menumbuh kembangkan budi pekerti siswa dengan pembudayaan ekosistem literasi sekolah yang diwujudkan dalam Gerakan Literasi Sekolah agar mereka menjadi pembelajar sepanjang hidupnya (Dewi \& Isnarmi, 2019). Gerakan Literasi Sekolah menekankan pada pembiasaan membaca bagi siswa sebelum dilaksanakan proses pembelajaran (Anindya et al., 2019; Anjani et al., 2019; Septiary \& Sidabutar, 2020).

Pada dasarnya kegiatan literasi memiliki keterkaitan erat dengan pendidikan karena literasi dipersepsi sebagai sebuah prasyaratan untuk masuk dalam kegiatan belajar dalam pendidikan (Rahmatunisa, 2017). Literasi merupakan kemampuan belajar untuk mengakses ilmu pengetahuan melalui membaca sebaliknya, literasi berarti kemampuan menggunakan keterampilan membaca dalam hal mendapatkan akses ke dunia pengetahuan, untuk mendapatkan informasi dari berbagai sumber, untuk mengevaluasi argument, dan juga belajar subjek yang benar-benar baru (Ainiyah, 2017). Pelaksanaan kegiatan literasi membaca bertujuan memperkenalan siswa tentang dasar - dasar membaca dan menulis, memelihara kesadaran bahasa, dan motivasi untuk belajar. Maka dari itu dijelaskan bahwa membaca merupakan kemampuan yang harus dimiliki oleh semua anak karena melalui membaca anak dapat belajar banyak tentang berbagai bidang studi. Beberapa penelitian yang dilaksanakan sebelumnya menyebutkan bahwa secara umum pelaksanaan kegiatan literasi sekolah sudah berjalan lancar siswa sudah mulai menyukai membaca, namun buku yang tersedia masih sangat kurang sehingga pengalaman membaca siswa sangat terbatas (Yunianika \& ., 2019). Penelitian selanjutnya juga menyatakan bahwa pelaksanaan program gerakan literasi sekolah di SDN Gugus Sungai Miai Banjarmasin berada pada tahap pembiasaan, sehingga masih membutuhkan bimbingan serta masih terdapat berbagai macam kendala dalam pelaksanaannya seperti kurangnya jumlah buku yang dimiliki sekolah serta masih terdapat beberapa siswa yang membaca secara asal-asalan (Batubara \& Ariani, 2018). Penelitian lainnya juga menyebutkan bahwa program GLS sudah dilaksanakan di sekolah dengan baik, pelaksanaan pembiasaan membaca dilakukan 15 menit di sekolah sudah sesuai tujuan nasional (Widayoko et al., 2018). Berdasarkan hasil tersebut dapat dikatakan bahwa secara umum gerakan literasi sekolah telah berjalan dengan maksimal, walaupun terdapat beberapa kendala di dalamnya. Hanya saja pada penelitian sebelumnya, belum terdapat kajian mengenai analisis pelaksanaan literasi membaca di kelas V SD, sehingga penelitian difokuskan pada hal tersebut dengan tujuan untuk untuk mengetahui bagaimana pelaksanaan literasi membaca tujuan penelitian ini untuk mengetahui proses pengembangan dan faktor pendukung dan penghambat literasi membaca.

\section{METODE}

Penelitian ini merupakan jenis penelitian deskriptif dengan menggunakan pendekatan kualitatif, untuk memperoleh gambaran mengenai pelaksanaan literasi membaca. Penelitian kualitatif merupakan suatu prosedur penelitian yang menghasilkan data deskriptif berupa ucapan atau tulisan dan perilaku orang-orang yang diamati. Subjek yang terlibat dalam penelitian ini yakni guru dan siswa kelas V di SDN 
004 Simpang Pulai Kecamatan Ukui Kabupaten Pelalawan. Pengumpulan data dalam penelitian dilakukan dengan menggunakan metode wawancara, observasi, angket, dan dokumentasi. Dengan instrumen berupa pedoman observasi dan kuisioner. Instrumen pedoman observasi digunakan untuk memperoleh data tentang bagaimana guru dalam pelaksanaan literasi membaca serta mencari data mengenai hambatan yang dialami oleh guru dalam pelaksanaan literasi membaca. Data hasil penelitian kemudian dianalisis menggunakan analisis deskriptif kualitatif dengan memaparkan hasil penelitian kemudian mengkaitkan dengan teori-teori yang sejalan.

\section{HASIL DAN PEMBAHASAN}

\section{Hasil}

Berdasarkan hasil wawancara, observasi dan dokumentasi ditemukan hasil bahwa kemampuan literasi di SDN 004 Simpang Pulai Kecamatan Ukui Kabupaten Pelalawan sangatlah rendah untuk mengembangkan kemampuan membaca peserta didik diperlukan strategi yang tepat supaya siswa semakin tertarik dan terlatih untuk membaca dan mencari informasi di lingkungan sekitarnya sehingga menjadi pengetahuan yang bermanfaat bagi dirinya sendiri. Oleh karena itu dengan adanya pelaksanaan literasi membaca di sekolah sangatlah tepat dan sangat penting bagi sekolah, apalagi sekolah dasar adalah tempat pertama untuk menanamkan dasar - dasar tentang literasi membaca kepada siswa. Pelaksanaan literasi membaca di SDN 004 Simpang Pulai Kecamatan Ukui Kabupaten Pelalawan dilaksanakan sejak tahun 2018, pelaksanaan ini diikuti dikarenakan ada didalam peraturan pembelajaran kurikulum 2013 kegiatan literasi membaca dilaksanakan setiap pagi sebelum jam pembelajaran dimulai. Kegiatan pelaksanaan literasi membaca di SDN 004 Simpang Pulai Kecamatan Ukui Kabupaten Pelalawan memiliki beberapa program yang terdiri dari membuat mading untuk dikelas, dan pojok baca. Adapun kegiatan literasi membaca di SDN 004 Simpang Pulai yakni, siswa membaca di depan kelas, guru becerita, dan siswa membuat karya seperti pantun, puisi dan cerpen.

Pelayanan lain yang mendukung literasi membaca di SDN 004 Simpang Pulai adalah pojok baca. Pemerintah juga telah bekerja sama dengan setiap sekolah untuk membuat pojok baca untuk siswa membaca buku dikelas. Pojok baca ini berfungsi untuk program yang mengondisikan siswa agar tidak suntuk atau gaduh dikelas. Buku - buku yang ada dipojok baca terdiri dari buku pengetahuan umum, buku pelajaran, buku cerita, komik dan cerpen. Selain itu pojok baca memiliki manfaat berupa memberikan suasana baru dikelas, juga disaat waktu luang atau jam istirahat bisa dimanfaatkan untuk siswa membaca dan menjadikan siswa senang dan gemar membaca dengan dibimbing guru. Program literasi membaca yang diadakan di SDN 004 Simpang Pulai terdiri dari membuat puisi, pantu, dan cerita pendek dari pengalaman siswa saat membaca atau pengalaman siswa itu sendiri. Program ini terlihat dari setiap siswa membuat puisi atau pantu karya mereka di dipamerkan di setiap kelas. Adapun yang membuat cerita pedek siswa akan membacakannya di depan kelas. Program ini dilaksanakan oleh guru disetiap sebelum ujian semester untuk penambahan nilai siswa yang aktif dalam pembelajaran. Program ini dilakukan oleh secara individu dan berkelompok tergantung siswanya mau seperti apa.

Selain terdapat kegiatan bercerita dan menyusun suatu karya tulis, pelaksanaan literasi membaca di SDN 004 Simpang Pulai Kecamata Ukui Kabupaten Pelalawan juga dilakukan dengan mengajak siswa berlatih dalam menganalisis isi teks, menggambarkan inferensi analitis atas teks, mengkritis teks, serta menampilkan secara kreatif. Pada pelaksanaan gerakan literasi sekolah, terdapat berbagai faktor pendukung dan penghambat pelaksanaan literasi. Faktor Faktor pendukung pelaksanaan literasi membaca di SDN 004 Simpang Pulai terdiri dari guru - guru yang semangat dalam melakukan pelaksanaan literasi membaca, adanya alokasi waktu setiap paginya sebelum pembelajaran, dan adanya kerja sama dengan orang tua siswa. Sedangkan faktor penghambatnya yakni ketersediaan sarana prasarana yang kurang memadai seperti buku-buku bacaan dan ada sebagian siswa yang belum lancar membaca.

\section{Pembahasan}

Berdasarkan hasil analisis data didapatkan beberapa temuan dalam penelitian ini, diantaranya adalah. Temuan pertama pada penelitian menunjukkan bahwa kemampuan literasi siswa kelas V SDN 004 Simpang Pulai Kecamatan Ukui Kabupaten Pelalawan masih tergeolong rendah, hal ini dikarenkana siswa belum terbiasa untuk melaksanakan kegiatan literasi secara rutin. Kurangnya minat serta kemampuan membaca siswa lebih banyak dipengaruhi oleh dorongan yang ada dalam diri siswa (Elendiana, 2020; Mardika, 2019). Sehingga guru sebagai tenaga pendidik dituntut untuk mampu memotivasi siswa, agar siswa lebih mengembangkan kemampuan membaca serta membangun kebiasaan membaca (Prasetyaningrum, 2019; Prastowo, 2020). Temuan kedua pada penelitian ini merujuk pada proses pelaksanaan kegiatan literasi. Berdasarkan pada hasil observasi dan wawancara didapatkan hasil 
bahwa kegiatan literasi pertama kali dilaksanakan pada tahun 2018. Kegiatan ini dilaksanakan dengan mengajak siswa untuk mambaca buku selam 15 menit sebelum jam pelajaran dimulai. Untuk menunjang proses pembelajaran literasi guru umumnya mengajak siswa untuk bercerita dan membuat karangan pendek. Kegiatan bercerita menjadi salah satu alternatif yang dapat digunakan oleh guru untuk meningkatkan ketertarikan serta motivasi siswa untuk membaca (Gusti, 2020; Nugraheni et al., 2019). Selain itu kegiatan membuat karangan pendek juga dapat meningakatkan kreatifitas serta kecapakan siswa pada aspek menulis (Alwi et al., 2021). Kegiatan literasi pada SDN 004 Simpang Pulai Kecamatan Ukui Kabupaten Pelalawan tidak terbatas hanya pada kegiatan bercerita dan menyusun karangan pendek, melainkan siswa juga diajak untuk berlatih dalam menganalisis isi teks, menggambarkan inferensi analitis atas teks, mengkritis teks, serta menampilkan secara kreatif. Kegiatan menganalisis isi teks merupakan kegiatan pengujian yang sistematis dan dapat direplikasi dari simbol-simbol komunikasi, dimana symbol ini diberikan nilai numerik berdasarkan metode statistik untuk menggambarkan isi komunikasi, menarik kesimpulan dan memberikan konteks (Sari, 2018). Melalui kegiatan menganalisis isi teks siswa akan mampu mehami dengan baik maksud serta makna yang terkandung pada teks yang dibacanya (Elendiana, 2020; Nugraha et al., 2018). Selanjutnya pada kegiatan menggambarkan inferensi analitis atas teks siswa diajak untuk membuat kesimpulan dari ungkapan atau makna kata sebuah cerita, terkadang siswa sering mendengar kata - kata tersebut tetapi belum menggetahui arti dari kata - kata tersebut, sehingga dirasa perlu untuk meningkatkan pemahaman siswa mengenai arti kata yang dibacanya, sehingga mampu mengkritisi teks yang telah dibaca (Anindya et al., 2019). Kegiatan mengkritisi teks merupakan kegiatan sangatlah bagus dilaksankan agar siswa mengetahui kesalahan atau solusi untuk sebuah karya (Nopilda \& Kristiawan, 2018). Sehingga nantinya siswa mampu menampilkan sebuah karya yang lebih kreatif, inovatif, dan sesuai dengan kaidah-kaidah kebahasaan.

Temuan ketiga, berkaitan dengan faktor pendukung dan penghambat pelaksanaan pembelajaran daring. Faktor pendukung pelaksanaan literasi membaca di SDN 004 Simpang Pulai terdiri dari guru guru yang semangat dalam melakukan pelaksanaan literasi membaca, adanya alokasi waktu setiap paginya sebelum pembelajaran, dan adanya kerja sama dengan orang tua siswa. Sedangkan penghambatnya adalah sarana prasarana yang kurang memadai seperti buku -buku bacaan dan ada sebagian siswa yang belum lancar membaca. Keberhasilan kegiatan literasi atau kegiatan pembelajaran lainnya tentu bergantung pada bagaimana guru menggandeng siswanya untuk belajar (Prastowo, 2020; Rahmatunisa, 2017). Guru yang mampu memotivasi serta meningkatkan semangat belajar siswa akan memberikan dampak pada peningkatan kemampuan siswa, begitu pula sebaliknya. Selain dipengaruhi oleh guru keberhasilan kegiatan literasi juga bergantung pada ketersediaan sarana dan prasarana (Anindya et al., 2019). Salah satu sarana penting dalam kegiatan literasi adalah buku, jika ketersediaan buku masih kurang maka pelaksanaan literasi juga akan terhambat, begitu pula berlaku sebaliknya. Hasil yang diperoleh pada penelitian ini sejalan dengan hasil penelitian terdahulu yang juga menyebutkan bahwa bahwa secara umum pelaksanaan kegiatan literasi sekolah sudah berjalan lancar siswa sudah mulai menyukai membaca, namun buku yang tersedia masih sangat kurang sehingga pengalaman membaca siswa sangat terbatas (Yunianika \& ., 2019). Penelitian selanjutnya juga menyatakan bahwa pelaksanaan program gerakan literasi sekolah di SDN Gugus Sungai Miai Banjarmasin berada pada tahap pembiasaan, sehingga masih membutuhkan bimbingan serta masih terdapat berbagai macam kendala dalam pelaksanaannya seperti kurangnya jumlah buku yang dimiliki sekolah serta masih terdapat beberapa siswa yang membaca secara asal-asalan (Batubara \& Ariani, 2018). Penelitian lainnya juga menyebutkan bahwa program GLS sudah dilaksanakan di sekolah dengan baik, pelaksanaan pembiasaan membaca dilakukan 15 menit di sekolah sudah sesuai tujuan nasional (Widayoko et al., 2018). Berdasarkan hal tersebut dapat dikatakan bahwa secara umum kegiatan literasi telah terlaksana dengan baik dan mampu meningkatkan kemampuan membaca siswa

\section{SIMPULAN}

Secara umum kegiatan literasi yang dilaksanakan di SDN 004 Simpang Pulai telah terlaksanakan dengan cukup baik, dimana siswa sudah mulai terbiasa untuk membaca selama 15 menit sebelum jam pelajaran dimulai. Kegiatan literasi yang dilaksanakan yakni bercerita, menyusun karangan pendek, menganalisis isi teks, menggambarkan inferensi analitis atas teks, mengkritis teks, serta menampilkan secara kreatif.

\section{DAFTAR PUSTAKA}

Ainiyah, N. (2017). Membangun Penguatan Budaya Literasi Media dan Informasi dalam Dunia Pendidikan. Jurnal Pendidikan Islam Indonesia, 2(1), 65-77. https://doi.org/10.35316/jpii.v2i1.63. 
Alpian, Y., \& Anggraeni, S. W. (2019). Pentingnya Pendidikan Bagi Manusia. Jurnal Buana Pengabdian, 1(1), 66-72. https://doi.org/10.36805/jurnalbuanapengabdian.v1i1.581.

Alwi, A., Rozak, A., \& Wiradinata, R. (2021). Penguatan Aspek Kreativitas Melalui Pembelajaran Menulis Teks Narasi Dengan Model Berbasis Proyek. Jurnal Pendidikan Bahasa Sekolah Pascasarjana, 10(2). https://doi.org/10.33603/jt.v10i1.5227.

Anindya, E. F. Y., Suneki, S., \& Purnamasari, V. (2019). Analisis Gerakan Literasi Sekolah Pada Pembelajaran Tematik. Jurnal Ilmiah Sekolah Dasar, 3(2), 238. https://doi.org/10.23887/jisd.v3i2.18053.

Anjani, S., Dantes, N., \& Artawan, G. (2019). Pengaruh Implementasi Gerakan Literasi Sekolah Terhadap Minat Baca Dan Kemampuan Membaca Pemahaman Siswa Kelas V SD Gugus II Kuta Utara. Pendasi: Jurnal Pendidikan Dasar Indonesia, 3(2). https://doi.org/10.23887/jpdi.v3i2.2869.

Ariyanti, M. (2017). Perbandingan Keefektifan Model Project-Based Learningdan Problem-Based Learningditinjau Dariketercapaian Tujuan Pembelajaran. Jurnal Pendidikan Matematika Dan Sains, 5(1). https://doi.org/10.21831/jpms.v5i1.13469.

Astawa, I. N. T. (2017). Memahami Peran Masyarakat Dan Pemerintah Dalam Kemajuan Mutu Pendidikan Di Indonesia. Jurnal Penjaminan Mutu, 3(2), 197. https://doi.org/10.25078/jpm.v3i2.200.

Batubara, H. H., \& Ariani, D. N. (2018). Implementasi Program Gerakan Literasi Sekolah Di Sekolah Dasar Negeri Gugus Sungai Miai Banjarmasin. Jurnal Pendidikan Sekolah Dasar, 4(1), 15. https://doi.org/10.30870/jpsd.v4i1.2965.

Dewi, Z., \& Isnarmi, I. (2019). Penanaman Karakter dalam Program Gerakan Literasi Sekolah (GLS) di SMP Negeri 18 Padang. Journal of Civic Education, 1(4), 350-362. https://doi.org/10.24036/jce.v1i4.322.

Elendiana, M. (2020). Upaya Meningkatkan Minat Baca Siswa Sekolah Dasar. Jurnal Pendidikan Dan Konseling (JPDK), 2(1), 54-60. https://doi.org/10.31004/jpdk.v1i2.572.

Fitriana, E., \& Ridlwan, M. K. (2021). Pembelajaran Transformatif Berbasis Literasi Dan Numerasi Di Sekolah Dasar Penulis. Jurnal Pendidikan Ke-SD-An, 8(2). https://doi.org/10.30738/trihayu.v8i1.11137.

Gusti, Y. (2020). Pengembangan Model Literasi melalui Dongeng dalam Memotivasi Membaca dan Menulis Berbasis Bahasa Indonesia. Studia Komunika: Jurnal Ilmu Komunikasi, 3(2), 34-43. https://doi.org/10.47995/jik.v1i1.8.

Hendriana, E. C., \& Jacobus, A. (2016). Implementasi Pendidikan Karakter Di Sekolah Melalui Keteladanan Dan Pembiasaan. Jurnal Pendidikan Dasar Indonesia, 1(2), 25-29. https://doi.org/ 10.26737/jpdi.v1i2.262.

Ismaniar. (2018). Optimalisasi Peran Keluarga Dalam Stimulasi Kemampuan Membaca Awal Anak Melalui Pendekatan Environmental Print. E-Tech: Jurnal Ilmiah Teknologi Pendidikan, 6(2). https://doi.org/10.24036/et.v2i2.101459.

Kamardana, gede, Lasmawan, I. W., \& Suarni, N. K. (2021). Efektivitas Gerakan Literasi Sekolah Terhadap Minat Baca Dan Hasil Belajar Di Kelas V Sekolah Dasar Gugus II Tejakula Tahun Pelajaran 2019/2020. Pendasi: Jurnal Pendidikan Dasar Indonesia, 5(1), 115-125. https://doi.org/10.23887/jurnal_pendas.v5i1.264.

Khotimah, K., Akbar, S., \& Sa'dijah, C. (2018). Pelaksanaan Gerakan Literasi Sekolah. Jurnal Pendidikan: Teori, Penelitian, Dan Pengembangan, 3(11), 1488-1498. https://doi.org/ 10.17977/jptpp.v3i11.11778.

Lubis, M. A. (2018). Pengembangan Bahan Ajar Komik Untuk Meningkatkan Minat Baca PPKN Siswa MIN Ramba Padang Kabupaten Tapanuli Selatan. Jurnal Tarbiyah, 25(2). https://doi.org/10.30829/tar.v25i2.370.

Mardika, T. (2019). Analisis Faktor-Faktor Kesulitan Membaca Menulis Dan Berhitung Siswa Kelas 1 SD. Dinamika Jurnal Ilmiah Pendidikan Dasar, 10(1). https://doi.org/10.30595/dinamika.v10i1.4049.

Megantara, K., \& Wachid, A. (2021). Pembiasaan Membaca dalam Pelajaran Bahasa Indonesia Melalui Gerakan Literasi Sekolah. Jurnal Onoma: Pendidikan, Bahasa, Dan Sastra, 7(2), 383-390. https://doi.org/10.30605/onoma.v7i2.1230.

Mirna, W., \& Rambe, N. R. (2021). Terhadap Proses Perkembangan Imajinasi Anak Melalui Kegiatan Membaca. Jurnal Maqasiduna, https://journal.mukhlisina.id/index.php/maqasiduna/article/view/7/2.

Nopilda, L., \& Kristiawan, M. (2018). Gerakan Literasi Sekolah Berbasis Pembelajaran Multiliterasi Sebuah Paradigma Pendidikan Abad Ke- 21. JMKSP (Jurnal Manajemen, Kepemimpinan, Dan Supervisi Pendidikan), 3(2). https://doi.org/10.31851/jmksp.v3i2.1862.

Nugraha, A. P., MS, Z., \& Bintoro, T. (2018). Hubungan Minat Membaca dan Kemampuan Memahami Wacana dengan Keterampilan Menulis Narasi. Indonesian Journal of Primary Education, 2(1), 19. 
https://doi.org/10.17509/ijpe.v2i1.11647.

Nugraheni, I., Harsiati, T., \& Qohar, A. (2019). Media Buku Cerita untuk Meningkatkan Kemampuan Membaca dan Menulis Siswa Kelas IV Sekolah Dasar. Jurnal Pendidikan: Teori, Penelitian, Dan Pengembangan, 4(3), 322. https://doi.org/10.17977/jptpp.v4i3.12085.

Prasetyaningrum, E. Y. (2019). Pengaruh Motivasi Belajar dan Kemampuan Berpikir Logis Terhadap Kemampuan Membaca Pemahaman Siswa SDN Kletekan Kabupaten Ngawi. Linguista: Jurnal $\begin{array}{llll}\text { Ilmiah Bahasa, Sastra, Dan } & \text { Pembelajarannya, }\end{array}$ https://doi.org/10.25273/linguista.v2i2.3696.

Prastowo. (2020). Penerapan Program Literasi Sebagai Peningkatan Kemampuan Baca Tulis Siswa Di SD Negeri Temas 01 Kota Batu. Jurnal Pendidikan Madrasah Ibtidaiyah, 1(3), 72-81. http://www.riset.unisma.ac.id/index.php/JPMI/article/view/3137/2823.

Rahmatunisa, W. (2017). Literasi Media Melalui Kajian Linguistik Fungsional di Indonesia. FON : Jurnal Pendidikan Bahasa Dan Sastra Indonesia, 11(2). https://doi.org/10.25134/fjpbsi.v11i2.726.

Rohman, S. (2017). Membangun Budaya Membaca Pada Anak Melalui Program Gerakan Literasi Sekolah. Jurnal Pendidikan Dan Pembelajaran Dasar, 4(1), 156. https://doi.org/ 10.24042/terampil.v4i1.2118.

Sari, I. F. R. (2018). Konsep Dasar Gerakan Literasi Sekolah Pada Permendikbud Nomor 23 Tahun 2015 Tentang Penumbuhan Budi Pekerti. Al-Bidayah: Jurnal Pendidikan Dasar Islam, 10(1), 89-100. https://doi.org/10.14421/al-bidayah.v10i1.131.

Sariani, N. W. (2020). Implementasi Program GLS Di SMP Negeri 1 Kuta Selatan Dalam Upaya Menumbuhkembangkan Minat Baca Siswa. Jurnal Pendidikan Kewarganegaraan, 8(1). https: //doi.org/10.23887/jpku.v8i1.23949.

Septiary, D., \& Sidabutar, M. (2020). Pelaksanaan program gerakan literasi sekolah (GLS) di SD Muhammadiyah Sokonandi. Epistema, 1(1), 1-12. https://doi.org/10.21831/ep.v1i1.32054.

Setiawan, D. (2018). Dampak Perkembangan Teknologi Informasi dan Komunikasi Terhadap Budaya. Jurnal Simbolika: Research and Learning in Communication Study, 4(1), 62. https://doi.org/10.31289/simbollika.v4i1.1474.

Sudiana, N. (2020). Upaya Meningkatkan Minat Baca Siswa Kelas VII SMP Negeri 2 Sukasada Tahun Pelajaran 2017/2018 Melalui Gerakan Literasi Sekolah dengan Pocari dan Puding. Journal of Education Action Research, 4(1), 10. https://doi.org/10.23887/jear.v3i4.23075.

Sujana, I. W. C. (2019). Fungsi Dan Tujuan Pendidikan Indonesia. Adi Widya: Jurnal Pendidikan Dasar, 4(1), 29. https://doi.org/10.25078/aw.v4i1.927.

Syahidin, S. (2020). Meningkatkan Minat Membaca melalui Gerakan Literasi Sekolah. ASATIZA: Jurnal Pendidikan, 1(3), 373-381. https://doi.org/10.46963/asatiza.v1i3.163.

Teguh, mulyo. (2017). Aktualisasi Kurikulum 2013 Di Sekolah Dasar Melalui Gerakan Literasi Sekolahuntuk Menyiapkan Generasi Unggul Dan Berbudi Pekerti. Prosiding Seminar Nasional, 1826. https://training.unmuhkupang.ac.id/index.php/jpdf/article/view/217/120.

Wandasari, Y. (2017). Implementasi Gerakan Literasi Sekolah (Gls) Sebagai Pembentuk Pendidikan Berkarakter. JMKSP (Jurnal Manajemen, Kepemimpinan, Dan Supervisi Pendidikan), 2(2). https: //doi.org/10.31851/jmksp.v2i2.1480.

Widayoko, A., H, S. K., \& Muhardjito, M. (2018). Analisis Program Implementasi Gerakan Literasi Sekolah (GLS) Dengan Pendekatan Goal-Based Evaluation. Jurnal Tatsqif, 16(1), 78-92. https://doi.org/10.20414/jtq.v16i1.134.

Yunianika, I. T., \& . S. (2019). Implementasi Gerakan Literasi Sekolah di Sekolah Dasar Dharma Karya Universitas Terbuka. Jurnal Ilmiah Sekolah Dasar, 3(4), 507. https://doi.org/10.23887/jisd.v3i4.17331. 